\title{
TO COMPARE THE EFFECTIVENESS \& TOLERABILITY OF MISOPROSTOL AS A CERVICAL RIPENING AGENT IN FIRST TRIMESTER ABORTION THROUGH SUBLINGUAL \& VAGINAL ROUTES OF ADMINISTRATION
}

Jayati Nath ${ }^{1}$, Snehal Shah ${ }^{2}$, Rina Sharma ${ }^{3}$.

1. Assistant Professor, Department of Obstetrics \& Gynaecology, Teerthanker Mahaveer Medical College \& Research Centre, Moradabad, Uttar Pradesh.

2. Senior Resident, Department of Obstetrics \& Gynaecology, Teerthanker Mahaveer Medical College \& Research Centre, Moradabad, Uttar Pradesh.

3. Professor, Department of Obstetrics \& Gynaecology, Teerthanker Mahaveer Medical College \& Research Centre, Moradabad, Uttar Pradesh.

\section{CORRESPONDING AUTHOR}

Dr. Jayati Nath,

Assistant Professor,

Obstetrics \& Gynaecology Department,

TMMCRC, TMU Campus, Delhi Road,

Moradabad, Uttar Pradesh.

Email- jayati.nath@yahoo.com

\section{HOW TO CITE THIS ARTICLE:}

Jayati Nath, Snehal Shah, Rina Sharma. "To Compare the Effectiveness \& Tolerability of Misoprostol as a Cervical Ripening agent in first Trimester Abortion through Sublingual \& Vaginal Routes of Administration". Journal of Evolution of Medical and Dental Sciences 2013; Vol2, Issue 25, June 24; Page: 4563-4567.

ABSTRACT:-OBJECTIVE: To compare the effectiveness and tolerability of misoprostol as a cervical ripening agent in first trimester abortion through sublingual and vaginal routes of administration.

MATERIAL AND METHODS: This study was carried out in the department of Obst. \& Gynae TMMC \& RC. A total of 120 patients were included in the study. They were divided in two groups

\section{GROUP A - 60 patients - sublingual}

\section{GROUP B - 60 patients - vaginal}

The drug was administered 3-4 hours before suction and evacuation by sublingual and vaginal routes.

Efficacy was assessed on the basis of time taken for ripening, dilatation achieved, duration of the procedure, intraoperative blood loss and pain. The patient's tolerability was noted on the basis of side effects.

RESULTS: The mean time taken for cervical ripening was more in the sublingual group as compared to the vaginal $(\mathrm{P}<0.001)$.The duration of suction and evacuation was less as compared to the vaginal route. The mean intraoperative blood loss was more in sublingual as compared to the vaginal group. The intraoperative pain score was comparatively lower $(\mathrm{P}<0.05)$ as compared to the vaginal. Side effects like loose motions, nausea vomiting were more with sublingual group.

KEY WORDS: misoprostol, $1^{\text {st }}$ trimester abortion, sublingual, vaginal route 


\section{ORIGINAL ARTICLE}

INTRODUCTION: Prostaglandins have revolutionized the treatment of abortion ${ }^{1}$. Mechanical dilatation of cervix before surgical abortion carries a risk of cervical injury and uterine perforation more so in the nulliparous and in previous caesarean patients ${ }^{2}$. Comparative studies of Sublingual oral vaginal misoprostol for cervical priming have been carried out in different parts of the world ${ }^{3-7}$.

The aim of this study was to determine the efficacy of $400 \mu \mathrm{g}$ of misoprostol through Sublingual versus vaginal routes for cervical ripening in the first trimester abortions before suction and evacuation. This study also evaluates tolerability, operative ease and blood loss with misoprostol by two routes.

MATERIAL AND METHODS: The present study was conducted in the department of obstetrics and gynaecology from July 2011 to June 2012 in TMMCRC. A total of 120 patients were included in the study, presenting with complaints of amenorrhoea of less than 12 wks of duration with a provisional diagnosis of either missed abortion or incomplete abortion. Informed consent of patients were taken and study was approved by institutional ethics committee.

\section{INCLUSION CRITERIA:}

$>$ Having single intrauterine pregnancy less than 10 wks by USG.

$>$ Patients giving informed consent.

$>\mathrm{Hb} \geq 9 \mathrm{gm} \%$.

\section{EXCLUSION CRITERIA:}

$>$ Patients with threatened or inevitable abortion.

$>$ Cardiovascular disease.

$>$ Known coagulopathy or blood dyscrasias.

$>$ Any uterine anomaly.

$>$ Any infection.

STUDY DESIGN AND CONDUCT: It was a prospective randomized study carried over a period of 1 year. The patients were divided into two groups of 60 each Group A sublingual and Group B vaginal. The patients were explained about the procedure and informed consent was obtained. Detailed clinical history including medical and surgical history with drug allergy was taken into account along with detailed clinical examination. Baseline investigations like Haemoglobin, Blood group, Bleeding time, Clotting time, renal function test, Liver function test, Urine routine analysis, Blood sugar were done. Misoprostol dose was decided from the previous studies $(3,8,9)$.

GROUP A:- $n=60$ (from 1-60) These patients were given sublingual $400 \mu \mathrm{g}$ of Misoprostol and examined after 3-4 hours.

GROUP B:- $n=60$ (from 61-120) These patients were given sublingual 400 $\mu$ g of Misoprostol inserted in the posterior fornix and examined after 3-4 hours.

Both the groups were assessed for efficacy on the basis of various parameters like cervical ripening, time taken for cervical ripening, cervical dilation, intraoperative blood loss and duration of procedure. Cervical dilation was measured with at least No. 8 or more size Hegars dilator passed though the cervical or without any resistance. Intraoperative blood loss was measured after sieving away the products and then subtracting the amount of liquor for the gestational age from the total aspirate. Associated complications were also taken into account. Before surgical evacuation (9) 
patients were asked about the side effects like nausea, vomiting, shivering, vaginal bleeding ranging from 0-3

$>0$ for no bleeding

$>1$ for minimal bleeding

$>2$ for bleeding like menstrual flow

$>3$ for severe bleeding

In all the two groups suction and evacuation was done with intra venous sedation i.e fortwin and phenargan and patients were discharged after 3 hours of the procedure if all the parameters were normal and no complications were observed.

STATISTICAL ANALYSIS: The data were recorded in mean \pm SD. ANOVA followed by a multiple comparison test (Krushal Wallis) was applied. F. value, degree of freedom and $\mathrm{P}<0.05$ were considered statistically significant.

The chi square test was applied wherever applicable.

OBSERVATION AND RESULT: The age and the obstetrical profile of the study population was comparable.

TABLE 1

\begin{tabular}{|l|l|l|l|}
\hline Parameters & $\begin{array}{l}\text { Sublingual Route } \\
\mathbf{n = 6 0}\end{array}$ & $\begin{array}{l}\text { Vaginal Route } \\
\mathbf{n = 6 0}\end{array}$ & Result \\
\hline Age & $36.0833 \pm 3.30$ & $26.25 \pm 3.8$ & $\begin{array}{l}\mathrm{F}=0.66 \\
\mathrm{P}=0.798\end{array}$ \\
\hline Gravida & $2.35 \pm 0.87$ & $2.45 \pm 0.88$ & $\begin{array}{l}\mathrm{F}=1.79 \\
\mathrm{P}=0.18\end{array}$ \\
\hline Parity & $1.15 \pm 0.75$ & $1.35 \pm 0.75$ & $\begin{array}{l}\mathrm{F}=2.104 \\
\mathrm{P}=0.15\end{array}$ \\
\hline $\begin{array}{l}\text { Amenorrhoea } \\
\text { (weeks) }\end{array}$ & $8.3 \pm 1.34$ & $8.37 \pm 1.36$ & $\begin{array}{l}\mathrm{F}=0.363 \\
\mathrm{P}=0.548\end{array}$ \\
\hline
\end{tabular}

The values are expressed as mean \pm SD

Table 1 - Epidemiological and obstetric profile of study patients.

Majority of the patients were between 20 - 30 year of age group and $\mathrm{P}_{1+0}$

TABLE 2: shows the comparison of different parameters in patients administered $400 \mu \mathrm{g}$ of Misoprostol.

\begin{tabular}{|l|l|l|l|}
\hline Parameters & $\begin{array}{l}\text { Sublingual Route } \\
\mathbf{n = 6 0}\end{array}$ & $\begin{array}{l}\text { Vaginal Route } \\
\mathbf{n = 6 0}\end{array}$ & Result \\
\hline Cervical ripening \% & 74.5 & 70.25 & $\mathrm{~F}=51.722$ \\
\hline $\begin{array}{l}\text { Time taken for } \\
\text { Cervical ripening } \\
\text { (hour) }\end{array}$ & $3.54 \pm 0.30$ & $4.39 \pm 0.77$ & $\mathrm{~F}=62.361$ \\
\hline $\begin{array}{l}\text { Cervical dilation } \\
\text { (mm) }\end{array}$ & $7.76 \pm 1.35$ & $6.9 \pm 0.796$ & $\mathrm{~F}=18.195$ \\
\hline $\begin{array}{l}\text { Intraoperative blood } \\
\text { loss (m) }\end{array}$ & $24.07 \pm 2.02$ & $24.87 \pm 3.04$ & $\mathrm{~F}=2.886$ \\
\hline $\begin{array}{l}\text { Duration of procedure } \\
\text { (min) }\end{array}$ & $7.36 \pm 1.60$ & $9.65 \pm 1.2$ & $\mathrm{~F}=74.624$ \\
\hline
\end{tabular}




\section{ORIGINAL ARTICLE}

The values are expressed as mean \pm SD (standard deviation) ANOVA test was used for statistical analysis.

DISCUSSION: Dilation and vacuum aspiration still remains the most widely accepted method for first trimester pregnancy termination.

Several studies have assumed the efficacy of PGs with or without mifepriston $10,11$. Mifepristone is expensive and it is highly desirable to develop a regimen without it. ${ }^{12}$ Misoprostal is the PG of choice as it is cheap and stable at room temperature and available in different dosage forms. ${ }^{13}$

The study shows that (fig 1, table 2) observes that the cervical ripening effect and the mean time taken by misoprostol by SUB LINGUAL route was better than the vaginal route. The observed differences can be attributed to the different absorption kinetics and more systemic bioavailability with the SUBLINGUAL route than the vaginal.

Our results were consistent with the ref 14, 3, 44, observation of Tangetal 154 and Saxena et al 8. The mean intraoperative blood loss was more in the vaginal group and it was compared to the SUB LINGUAL group as it was comparable to the observations made by Shagufta et al. ${ }^{15}$

The total duration of surgery was less in the SUB LINGUAL group which was due to better cervical ripening and dilation achieved in this group. These results are different with the studies of Saxena et al. ${ }^{8}$

The observed side effects like abdominal pain, loose motions, vaginal bleeding and nausea and vomiting were quite different from the earlier studies of Tang et al ${ }^{15}$ it could become of multiple doses used in this study.

Vaginal bleeding was more in the vaginal group; this observation was also reported by study done by Shagufta et al ${ }^{15}$. This could be attributed to sustained peak plasma concentration in this route.

Many clinical studies have shown that the vaginal route is superior to oral misoprostol in termination of pregnancy $\mathrm{N}$ jai et al ${ }^{16}$. However administration of oral drug with water $3 \mathrm{hr}$ before operation may cause problems especially if the patient requires GA.

Sublingual Misoprostol in medical termination of pregnancy has been studied ${ }^{17}$. The buccal mucosa being very vascular and misoprostol tablet being soluble in water dissolves within 10 min. of administration ${ }^{14}$. This route is convenient to use avoid vaginal administration.

The present study has few shortcomings as it was not a placebo controlled trial. The No. of patients was relatively less, repeat dose, single dose and pharmacokinetic parameters while comparing these routes were not studied for the comparative results of the study.

CONCLUSION: Sublingual Misoprostol is an effective and favourable cervical ripening agent for $1^{\text {st }}$ trimester abortions.

\section{REFERENCES:}

1. Niinimaki M, Joupilla P, Martikainen H, Talvensaari - Mattila A. A randomised study comparing efficacy and patient satisfaction in medical or surgical treatment of miscarriage FertilSteril - 2006; 86:367-72. 


\section{ORIGINAL ARTICLE}

2. Royal college of Obstetricians and Gynaecologists. Guidelines for induced abortion. Guideline No. 11 London. RCOG press; 1997:1-10.

3. Saxena P, Salhan S, Sarda N. Sublingual versus vaginal route of misoprostol for cervical ripening prior to surgical termination of first trimester abortion. Eur J. obstet Gynaecol Reprod Biolo. 2006; 125:109-13.

4. Caliskan E, Filiz T, Yucesoy G, Coskun E, Vural B, Coracki A. Sublingual versus vaginal misoprostol for cervical ripening PRIOR to manual vacuum aspiration under local anaesthesia. A randomised study. Eur J Contracept Reproductive health care. 2007; 12:372-7.

5. Lawrie A, Penny G, Templeton A. A randomised comparison of oral and vaginal misoprostol for cervical. Primary before suction termination of preg. $\mathrm{Br} J$ obstet Gynaecol. 1916; 103:1117-9.

6. Cakir L, Dilbaz B, caliskan E, Dede FS, Dilbaz S, Haberal A. Comparison of oral and vaginal misoprostol for cervical ripening before manual vacuum aspiration of first trimester pregnancy under local anaesthesia : A randomised placebo controlled study contracept 2005; 71:337-41.

7. Saxena P, Sathan S, Sarda N. comparison between the sublingual and oral route of misoprostol for pre abortion cervical primary in first trimester abortion. Hum Reprod. 2004; 19:77-80.

8. Saxena P, Sarda N, Salhan S, Nandan D. A randomised comparison between sublingual oral and vaginal route of misoprostol for pre-abortion cervical ripening in first trimester pregnancy termination under local anaesthesia. Aust NZ] obstetgynaecol 2008; 48:101-6.

9. Vimala N, Mittal S, Kumar S, Dadhwal V, Sharma Y. A randomised comparison of sublingual and vaginal misoprostol for cervical primary before suction termination of first trimester pregnancy.

10. Mckinly N, Thong KJ, Baird DT. The effect of dose of mifepristone and gestation on the efficacy of medical abortion with mifepristone and misoprostol. Hum Reprod. 1993; 8:1502-5.

11. Tang OS, Lau WN, Ng EH, Lee SW, Ho PC. A prospective randomized study to compare the use of repeated doses of vaginal with sublingual misoprostol in the management of first trimester silent miscarriages. Hum Reprod. 2003; 18:176-81.

12. Tang OS, Miao BY, Lee SW, Ho PC. Pilot study on the use of repeated doses of vaginal with sublingual misoprostol in the management of first trimester silent miscarriages. Hum Reprod. $2002 ; 17: 654-8$.

13. Tang OS, Mok KH, Ho PC. A randomized study comparing the use of sublingual to vaginal misoprostol for pre - operative cervical priming prior to surgical termination of pregnancy in the first trimester. Hum Repord. 2004; 19:1101-4.

14. Negai SW, Chan YM, Tang OS, Ho PC. The use of misoprostol for pre-operative cervical dilation prior to vacuum aspiration: A randomized trial. Hum Reprod. 1999; 14:2139-42.

15. Ho PC, Ngai SW, Liu KL, Wong GC, Lee SW. Vaginal misoprostol compared with oral misoprostol in termination of second - trimester pregnancy. Obstet Gynecol. 1997; 90:735-8. 